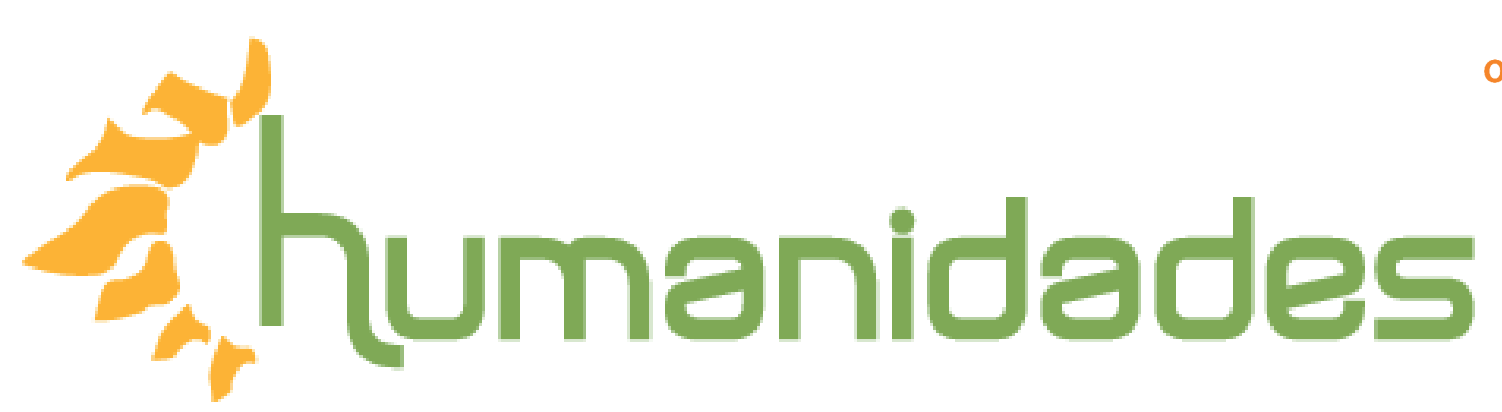

Revista de la Escuela de Estudios Generales, Universidad de Costa Rica

Julio-diciembre, 2018 •Volumen 8, número 2 • EISSN 2215-3934 •pp. 1-17

Recibido: 26-Setiembre-2017 Aceptado:26-Febrero-2018

\title{
Las marcas estructurales de El mártir del sacramento, san Hermenegildo, de Sor Juana Inés de la Cruz: ver- sificación, canto y escenografía.
}

DOI: http://dx.doi.org/10.15517/h.v8i2.33337

\section{Máster Carlos Enrique Mackenzie Rebollo}

Máster en Humanidades. Universidad Nacional Autónoma de México, México.

Correo electrónico:carlos.emackenzie@gmail.com

Todos los derechos reservados. Universidad de Costa Rica. Esta revista se encuentra licenciada con Creative Commons. Reconocimiento-NoComercial-SinObraDerivada 3.0 Costa Rica. Correo electrónico: humanidades@ucr.ac.cr / Sitio web: http://revistas.ucr.ac.cr/index.php/ humanidades 


\title{
Las marcas estructurales de El mártir del sacramento, san Hermenegildo, de Sor Juana Inés de la Cruz: versifi- cación, canto y escenografía.
}

\section{Resumen}

En el presente trabajo se analizó la función estructural de los pasajes cantados del auto sacramental El mártir del sacramento, san Hermenegildo. Acompañado de formas métricas poco frecuentes y de elementos escenográficos suntuosos, los pasajes cantados en este auto son importantes para el desarrollo de la diégesis; la combinación de estos elementos indica una superposición de espacios importante, que nos lleva desde los conflictos interiores de Hermenegildo hasta las repercusión de estos en su exterior.
Palabras claves: Versificación, estructura, canto, escenografía, auto sacramental

\section{The estructural marks of El mártir del sacramento, san Hermenegildo, by Sor Juana Inés de la Cruz: versifica- tion, sing and scenography.}

\begin{abstract}
In this paper, the structural function of Elmartirdel sacramento, san Hermenegildo's sung parts was analyzed. Attached to unusual metric forms and sumptuous scenographic elements, the sung parts of this auto are important to the story development. The combination of these elements indicates an important space overlap, leading us from the inner conflicts of Hermenegildo to the impact of these on the outside.
\end{abstract}

Keywords: Versification, structure, singing, scenography, auto sacramental 
Las marcas estructurales de el mártir del sacramento...

Los pasajes cantados son parte constitutiva del género sacramental: se trata de segmentos privilegiados para transmitir el mensaje dogmático, condensar el conflicto entre las fuerzas malignas y cristianas que se desarrollan en la trama, o en su defecto, el enfrentamiento de ambas fuerzas, pero no es la única función que cumplen. En palabras de Ignacio Arellano y J. Enrique Duarte (2003), “cuando el auto sacramental desarrolla sus estructuras, la función de la música crece para convertirse en verdaderos oratorios u óperas sagradas" (p. 84). Díez Borque (2000), en un brillante estudio sobre la recepción de los pasajes cantados de los autos sacramentales de Calderón de la Barca por parte del público que asistía al espectáculo, crea un catálogo de funciones de acuerdo a su recepción: “funciones vinculadas a la oración y práctica litúrgica —encomendadas [...] al texto cantado_-” ( p. 148). Entre las que menciona el profesor Díez Borque, están el canto como oración para pedir misericordia, piedad o clemencia, para alabar, rendir culto, suplicar, solicitar ayuda o favor de dios (Díez Borque, 2000, pp. 160-161); la alabanza pura, sin hacer ningún tipo de petición (Díez Borque, 2000, p. 165); la alabanza imperativa, que tiene un vínculo más fuerte con el receptor, dado que lo incita a formar parte del canto (Díez Borque, 2000, p. 167). También se da una oposición de tres coros con mensaje distinto cada uno, o una oposición entre dos, que "refuerza el mensaje por contraste, a veces violento" (Díez Borque, 2000, p. 170-171), y por último, también se da "la exposición doctrinal directa y de explicación de los hechos para garantizar y facilitar la comprensión del mensaje” (Díez Borque, 2000, p. 177).

En cuanto a la incidencia estructural de los pasajes cantados en los autos sacramentales, se ha insistido en su función meramente tonal. Para Françoise Gilbert, un pasaje cantado "puede implicar unas variaciones métricas no significantes desde el punto de vista estructural" (2006a, p. 168). Esto quiere decir, en palabras de Marc Vitse, que se trata de una forma métrica englobada (1998, p. 50), intercalada entre una tirada de versos más amplia con una función que sí resulta significativa. Sin prestar atención a la función doctrinal que cumple, su relevancia dramática dentro del auto o la forma en que se integra al texto1, el valor de los pasajes cantados solo se ha observado como una variación métrica y tonal insertada dentro de una tirada mayor de versos (sea esta una microsecuencia o macrosecuencia). Aunque no se pretende ser reduccionista en cuanto al análisis estructural de la versificación propuesto por Vitse, es evidente que el interés por interpretar cada forma estrófica y no estrófica que compone un drama es escaso frente a las circunstancias que implican las mutaciones métricas, pues afirma que 
"tal enfoque conlleva que no me interesaré por la naturaleza de las formas métricas anteriores o posteriores al cambio considerado, sino sola y exclusivamente por el fenómeno del cambio en sí” (Vitse, 1998 p.50)

Este procedimiento, no obstante, ha tenido una nutrida e interesante discusión respecto a la composición formal del teatro aurisecular, y particularmente sobre los autos sacramentales2.

Aunque es una herramienta útil para el análisis de la estructura de la dramaturgia, se corre el riesgo de que el valor de los pasajes cantados sea reducido a un cambio de versificación (una forma englobada) sin mayor incidencia. Veamos un ejemplo de El cordero de Isaías, auto de Calderón de la Barca que analiza Françoise Gilbert: la salida de unos personajes y la entrada de otro está concatenada por la repetición de unos versos cantados. Afirma Gilberth que "la casi concomitancia de la entrada y salida de los diferentes protagonistas, materializada en el texto por el hecho de que el Demonio entra repitiendo en forma interrogativa las últimas palabras pronunciadas por los precedentes protagonistas («¿Que espira su autor o espira / toda la Naturaleza?» vv. 267-268), indica la continuidad del tiempo dramático que existe entre Al a y Alb" (2006b, p. 169). Esta técnica da la impresión de que no hay un cambio geográfico o temporal en la entrada/salida de personajes. En Lavida es sueño,primeraversióndelauto, hay unatécnica semejante y más extensa:

Música: Cuanto en Fuego, Aire, Agua y Tierra...

La Sombra sale por una parte y por otra se van; y la Sombra repite lo que cantan

$\begin{array}{ll}\text { Sombra: } & \text { Cuanto en Fuego, Aire, Agua y Tierra... } \\ \text { Música: } & \text {...vuela, brilla, sulca y yerra... } \\ \text { Sombra: } & \text {...vuela, brilla, sulca y yerra... } \\ \text { Música: } & \text {...y en sí las obras encierra... } \\ \text { Sombra: } & \text {...y en sí las obras encierra... } \\ \text { Música: } & \text {...de Poder, Ciencia y Amor... }\end{array}$

¡Bendecid al Señor!

Sombra: ...de Poder, Ciencia y Amor...

¿Bendecid al señor?

(Calderón, 2012, vv. 488-497) 
Las marcas estructurales de el mártir del sacramento...

Las réplicas de la Sombra en La vida es sueño y la repetición del Demonio en El cordero de Isaías no sólo implican que no hay cambios en el espacio escénico, sino que también se infiere que salen de un lugar que está más allá del visible en el tablado, lo que García Barrientos llama espacio latente contiguo (2007, pp. 133134)3. Esta multiplicidad espacial también es evocada por los anónimos personajes "Coro" o "Música" a través de su intervención fuera de escena, excediendo su función estructural de mero "cambio de tono".

No todos los pasajes cantados están en boca del "Coro", la "Música" u otro tipo de personaje que permanece fuera de escena y de cualquier identificación concreta. Los pasajes cantados también pueden estar en boca de caracteres que están inmiscuidos en la trama, y tanto la música como el canto tienen finalidades estructurales y evocadoras concretas. En este sentido, el presente análisis sobre el canto y la música del auto El mártir del sacramento, San Hermenegildo tiene por objeto considerar este tipo de pasajes no solo como conductores del mensaje dogmático (en las distintas formas que menciona Díez Borque) o que tiene valor formal solo por el cambio de tono (por la variación métrica), sino como una forma de organizar el auto en conjunto respecto a los aspectos escénicos que resaltan el discurso que contienen y las incidencias estructurales que implica el canto en este auto sorjuanino.

El mártir del sacramento tiene 1962 versos en total, de los cuales 1408 son romances, es decir, más del setenta por ciento de la obra está escrita en octosílabos asonantes, y los restantes 554 versos están distribuidos entre décimas, silvas, octavas reales, lira sextina, dodecasílabos asonantes, romancillos esdrújulos, sextina de rima alternada, romancillos y endechas. No será difícil advertir que cada estilo métrico tiene una función específica en el auto de sor Juana4 si se considera que, con excepción de las silvas y el romancillo, el resto de los tipos de versificación aparece solo en una ocasión en toda la obra5. Quizá el caso más tipificado de textos cantados sea el del romancillo, forma métrica más común para este tipo de pasajes en los autos sacramentales. Por lo general se utilizan para dar fin a gran parte de las piezas que conforman este género teatral6. Resultan más llamativas, por su escasa frecuencia de uso, las liras sextinas, las liras asonantadas, los dodecasílabos con rima asonante y los octosílabos esdrújulos

Leonor Fernández, en su análisis sobre la versificación de El divino Narciso (2013) 
señala que sor Juana siguió los pasos de Calderón de la Barca para componer sus autos sacramentales, y añade que no solo "se muestra como la perfecta discípula que conoce y sigue el paradigma del maestro, se nos revela también como una artista original e innovadora que no sólo domina la técnica, sino que experimenta con ella y la explota al máximo" (p. 121), es decir, no se limita a la llana imitación de su modelo madrileño, como ápice de la escritura dramática sacramental, sino que sor Juana experimenta e innova en la composición de sus creaciones destinadas para el corpus. El mártir del sacramento tiene una estructura en dos niveles con relación al personaje principal, que interactúan entre sí para el progreso de la fábula. Ambas están imbricadas entre sí y se diferencian por las formas métricas que la monja gerónima emplea en cada parte, además de que el nivel interno tiene pasajes cantados acompañados de música para la expresión de los personajes alegóricos. En este sentido, la conjunción de los tres elementos (métrica, música y personajes) evidencia la finalidad de estructurar el texto en dos niveles: el interior de Hermenegildo, evocado por los personajes alegóricos que están de parte del bando católico, y el exterior, el enfrentamiento del mártir con su padre fundamentado en las diferencias religiosas de cada uno.

Se trata, entonces, del espacio interno y externo del mismo personaje, licencia que sor Juana se puede tomar gracias a la naturaleza del auto sacramental: la alegoría como principal figura retórica, capaz de significar a través de casi cualquier signo un sentido más profundo del anecdótico. Octavio Paz, en Las trampas de la fe, no alcanza a percibir estos hechos en el auto sorjuanino; su opinión es muy negativa respecto a El mártir del sacramento:

Es obra a la que se le ven los andamios y a la que le faltan dos o tres ventanas y una escalera [...] Sor Juana fue insensible a esta historia terrible, a la vez drama entre gente de la misma sangre y conflicto político y religioso [...] el lector moderno se siente ofendido por la parcialidad con que se relatan los hechos y por el mismo simplismo rudimentario de los caracteres y las ideas. (1982, p. 454)

No es que se le falte "construcción", siguiendo la analogía de Paz, sino que la misma sor Juana ha dejado los 'andamiajes' visibles; en otras palabras, para entender la forma externa (el conflicto entre arrianos y católicos, y más precisamente, entre Hermenegildo y su padre), hay que entender qué lo impulsa desde el interior, es decir, los andamiajes tan sin propósito, como juzga el poeta mexicano, representa- 
Las marcas estructurales de el mártir del sacramento...

tados por las Virtudes. Más adelante, Paz (1982) agrega: “es una obra hecha de prisa y a la que afean descuidos estéticos e imperfecciones morales" (p. 455). Es desafortunado que el ensayista y poeta mexicano no lograra captar la esencia de un auto sacramental: el enaltecimiento de la eucaristía (esencial para el género) y la forma en que la gran escritora novohispana lo estaba expresando (estructura en dos partes superpuestas).

Cada pasaje que se desarrolla con alguna forma poemática que sobresale por su poca asiduidad es cantado por personajes alegóricos: los dodecasílabos asonantes, las liras asonantadas y las dos tiradas de romancillos los cantan personajes del lado católico (Fe, Justicia, Verdad, Paz y Misericordia), mientras que el romanci1lo con palabras esdrújulas7 al final es cantado por personajes del bando arriano. Desde el inicio de la obra, el espacio es dominado por los personajes alegóricos, es decir, nos encontramos en el interior de Hermenegildo. Los veinte versos de apertura en romance que Fe recita son seguidos del pasaje de dodecasílabos8 en el que se invocan a las Virtudes. Este pasaje breve y enmarcado por dos tiradas en romance (es decir, está englobado) resulta llamativo por el contraste que se logra entre ambas formas métricas: una serie de octosílabos, bastante comunes, cuyo uso es recurrente y de gran porcentaje en el teatro barroco en general, y en este auto en particular, en la que se intercala una serie de versos poco usuales, puestos de relieve por la música que los acompaña, y más aún con los efectos escénicos (la tramoya) con que aparecen los personajes:

(canta:)

¡Venid, venid, pues la Fe es quien os llama, para hacer experiencia de quién resalta en un pecho en que todas tenéis morada; ¡Venid, venid, virtudes!

(dentro:)

¿A cuáles llamas?

Fe A aquellas que parece que son contrarias; y así, la Verdad venga para apurarla.

(Aparecen en el segundo carro, la Verdad con un espejo, la Misericordia con un ramo de oliva, la Paz con una bandera blanca, la Justicia con un peso y una espada; cada una, en una nube.). (Cruz, 1995, vv. 21-26) 
Las Virtudes salen a escena en 'nubes' sujetas a un canal (Hernández Araico, 2008, p. 289), caracterizadas por elementos de su indumentaria que permiten identificar a los personajes, como indica la acotación. Todo el aparato espectacular utilizado resalta de forma visual el pasaje de dodecasílabos, en contraposición al siguiente segmento, un extenso monólogo en romance en boca de Fe. El mismo contraste se logra de forma auditiva por el abrupto cambio entre la versificación dodecasílaba y el romance, entre el canto y el recitado, respectivamente, de estas mismas formas métricas. Hay que recordar que seguimos en el plano interior de Hermenegildo, pues se trata de su Fe y sus Virtudes.

El espacio interior, es decir, la inmersión a lo que sucede dentro de Hermenegildo, se desarrolla desde el v. 1 hasta el v. 213 y no se limita al pasaje de dodecasílabos cantados. Es decir que desde el inicio de la obra hasta que despierta el mártir, estamos presenciando el conflicto desde su interior; no obstante, hay que considerar que durante el canto se presentan los personajes alegóricos, versos con los que sor Juana acompaña el gran aparato escénico con que salen. Subrayar la salida a escena de estos caracteres implica la gran importancia que tienen dentro del drama: impulsan a Hermenegildo a defender e instaurar la religión católica u honrar a su padre (el conflicto interno del santo sevillano).

También hay contraste entre la disposición que tienen los carros de los que salen los cinco personajes, según la acotación inicial del texto, “Ábrese el primer carro, y aparece la Fe en un trono" (Cruz, 1998, acot. v. 1)9 y la antes citada que indica la forma en que aparecen las virtudes; Susana Hernández Araico (2008) señala que la disposición de los carros con respecto al tablado fijo queda de la siguiente manera: el carro uno y dos, que son los laterales, son los carros de la Fe y las Virtudes respectivamente; el carro tres, del presente diegético o de la fábula, al frente, y el cuarto, que está al fondo, lo denomina como el carro del "mito político-nacional” (p. 288-289). Esta consideración es importante porque destaca, respecto a los carros de la Fe y las Virtudes (el primero y segundo), sus espacios, en un sentido profundo, que representan el interior del Hermenegildo, donde se desarrolla el "conflicto interior, promovido por las Virtudes, entre la fidelidad a su padre y la fidelidad a Dios" (Worley, 2011, p. 106), y evidencia la interacción indirecta entre los personajes alegóricos y Hermenegildo, como se verá más adelante.

El siguiente pasaje cantado sucede al terminar el mencionado monólogo de Fe en romance. Al finalizar el extenso parlamento, se indica en el texto: "Ábrese el tercer carro y aparece una tienda de campaña, y en ella Hermenegildo 
Las marcas estructurales de el mártir del sacramento...

dormido; y cantan las Virtudes" (Cruz, 1995, acot. v. 189); mientras el mártir sevillano duerme, las Virtudes cantan a manera de coros opuestos (Díez Borque, 2000, pp. 170-171): Justicia y Verdad lo alientan para declararle la guerra a su padre, mientras que Paz y Misericordia lo exhortan a que instaure la religión católica de forma pacífica. Se intercalan parlamentos recitados y cantados, también se distingue con la versificación entre uno y otro: los personajes alegóricos, a manera de coros opuestos, cantan en liras asonantadas de rima alternada, mientras las intervenciones de Hermenegildo son en romance10, aunque ambas formas métricas quedan cohesionadas porque comparten la rima á-a. Es obvio que Sor Juana quiera diferenciar los discursos, los "coros opuestos" de las Virtudes y las dudas que le crean a Hermenegildo de las intervenciones de este mismo personaje porque en parte busca resaltar el mensaje dogmático mediante canto de los personajes alegóricos, además de que pone de relieve, nuevamente, la diferencia entre el interior y el exterior del mártir. Es decir, sor Juana enfatiza los distintos espacios: el de las Virtudes, superpuesto al espacio histórico del santo sevillano. Cuando la escena comienza, la acotación indica que debe estar dormido (Cruz, 1995 acot. v. 189), y se despierta por la perturbación creada en su interior: "despierta el rey Hermenegildo" (Cruz, 1995, acot. v. 213), una vez terminado el canto de las Virtudes. No obstante, él no logra ver, pero sí oír a Paz, Justicia, Misericordia y Verdad:

Y es que impresas en el alma (aunque falten los sentidos), las especies que guardadas tiene mi imaginativa, mientras el cuerpo descansa, se representan tan vivas que lo que es sólo fantasma finge tanta corpulencia, que aún ya despierto, jurara que oigo a la Misericordia...

(El mártir: vv. 221-230)

Aunque carece de seguridad ante lo que ve, "finge corpulencia", sí jura que escucha el canto que lo alienta a la batalla, y el otro que lo invita a hacer las paces con su padre. Antes de que pueda determinar algo, entra un paje y las Virtudes se esconden (Cruz, 1995, acot. v. 44). El plano interno que explicita la batalla personal del mártir, queda suspendido por la abrupta interrupción, por lo que el santo se ve 
obligado a prestar atención solo a lo externo (al plano historial). Es evidente el esfuerzo de la monja jerónima por diferenciar ambos planos y cómo influye uno en el otro, pues el conflicto bélico entre católi$\cos \mathrm{y}$ arrianos tiene su raigambre en el conflicto interno del santo mártir incitado desde su interior por los personajes alegóricos mediante sus cantos.

En contraste con esta interacción de 'oídas', Leovigildo sí ve a los personajes alegóricos que lo circundan. La Fantasía del regente, que se manifiesta como sombra esquiva, al ser alcanzada dialoga con el rey godo y da la indicación de que salgan al tablado España y Fama en un trono, con una salida a escena bastante llamativa según la acotación: "Descúbrese un trono, y en él España armada, con cetro y manto imperial, como se ha dicho; a un lado la Fama y a otro un aparador rico con coronas y cetros; y canta la fama" (Cruz, 1995, acot. v. 932); estos personajes alegóricos le muestran en desfile a los reyes que antecedieron a Leovigildo. La Fama canta los versos esdrújulos, un verdadero alarde técnico de sor Juana11, en los que incita a Leovigildo a una resolución bélica para el conflicto con su hijo:

Oigan el eco horrísono de mis acentos bélicos, desde el confín antártico, hasta su opuesto término. ¡Óiganlo! ¡Atiéndanlo!

De España glorias ínclitas oiga el planeta délfico, de sus dominios árbitro y de sus luces émulo. ¡Óiganlo! ¡Atiéndanlo!

(Cruz, 1995, vv. 933-942)

Nótese que, pese a la rima alternada, donde solo los versos que riman debieran ser forzosamente esdrújulos, todos los versos, sin importar que se trate de los sueltos, no dejan la misma acentuación en antepenúltima sílaba, que junto a toda la parafernalia escénica que acompaña el pasaje, resulta un fragmento altamente vistoso, complejo en cuanto a sus conceptos y auditivamente llamativo. Después del canto, van pasando uno a uno los reyes godos. El último verso de la cita anterior queda como estribillo después de cada una de las intervenciones de los antepasados. El conjunto de romancillo (esdrújulos cantados) y romance (el desfile de los reyes godos), 
Las marcas estructurales de el mártir del sacramento...

en términos estructurales queda englobado, haciendo un fuerte contraste con las silvas que lo enmarcan, y acompañado de un gran aparato escénico. También el espacio juega un papel importante: no hay que olvidar que ahora se utiliza el cuarto carro, el del mito "político-nacional”, como lo nombra Hernández Araico (2008, p. 289), en el que aparece todo el aparato escénico para la salida y participación en escena de la Fama, España y los reyes godos, segmento que pertenece a un segmento del pasado que se superpone al 'ahora' de la obra; es decir, nuevamente se superpone un plano sobre el otro, aunque no tiene la misma complejidad que tuvo el primer pasaje cantado.

Los dos últimos pasajes son romancillos cantados. Uno sucede cuando Apostasía intenta persuadir a Hermenegildo de convertirse en arriano y finge que su intento es ayudarlo a obtener el perdón de su padre. Antes de comenzar el debate entre ambos personajes sobre las creencias que cada uno tiene, Fe aparece cantando y convoca de nuevo a las Virtudes para socorrerlo durante la discusión. En esta ocasión el contraste métrico no es tan fuerte: el breve diálogo del santo y el prelado está escrito en romance, mientras el canto, como mencioné, es un romancillo; ambas formas quedan cohesionadas porque comparten la rima asonante é-o, que se conservará hasta el final del auto. Es probable que al finalizar el conflicto interior de Hermenegildo, la intervención de las Virtudes ya no necesite tanto realce, pues ahora sus parlamentos, aún cantados, sirven de apoyo al mártir, en lugar de crear un conflicto a dos coros como sucedió al inicio de la obra. No obstante, los personajes alegóricos no son visibles para nadie, ni para Hermenegildo, ni para Apostasía, por lo que nuevamente se superponen los espacios: por un lado, el debate religioso que culmina con el sacrificio del santo sevillano, y el interior de este, desde donde las Virtudes dan aliento y lo incitan a perseverar en la verdadera fe. La lid verbal termina con la muerte de Hermenegildo, pues no acepta recibir el sacramento de Apostasía. El sacrifico que se representa con el verdugo cortando su cabeza, recogido de la tradición icónica del mártir, explica Hernández Araico (2008, p. 290), enaltece las creencias católicas al uso de la época, en especial la eucaristía, fin último de los autos sacramentales. Seguido, salen a escena nuevamente la Fe y las Virtudes cantando las endechas finales que exaltan más el sacrificio del santo sevillano: 
Fe: $\quad$ Pues murió Hermenegildo,

y en el solio supremo,

al laurel inmortal

trocó el caduco cetro.

Música: ¡llore, llore la tierra,

y cante, cante el cielo!

(Cruz, 1995, vv. 1970-1912)

Para concluir, se puede afirmar que los pasajes cantados, no sólo considerados en su función estructural como un segmento englobado, organizan el conflicto interior de Hermenegildo, y sirven para dramatizar sus dudas y apoyar sus decisiones en el momento crucial; más allá de poner de relieve los aspectos dogmáticos del auto (de los que no está exento) muestra el plano interior que repercutirá en los sucesos históricos (lo que se cuenta) del auto; gracias a estos pasajes, conocemos de primera mano y con carácter dogmático, los motivos que llevan a Hermenegildo a tomar las armas contra su padre. Por otro lado, cabe destacar una diferencia sustancial entre los pasajes cantados de las alegorías "católicas" y las "arrianas": Hermenegildo solo escucha a las Virtudes (pues son parte de su interior) sin lograr verlas totalmente (recuérdese la cita del parlamento del santo sevillano, que las ve como sombras y no está totalmente seguro de observarlas), mientras que Leovigildo es capaz de ver todo el aparato que le presenta Fantasía para convencerlo de tomar las armas en contra de su hijo y defender sus creencias. La contraposición ver/oír resulta una forma en la que sor Juana resalta la fe verdadera de la falsa, pues el sentido de la fe por excelencia es el oído, mientras que la vista es engañadora, en palabras de Hernández Araico (2008): “Igualmente, en todos los autos de Calderón se desvaloriza verbalmente el sentido de la vista y se ensalza el oído como el más propicio para la fe" (p. 290). La propia Fe en el auto se encarga de recordarlo:

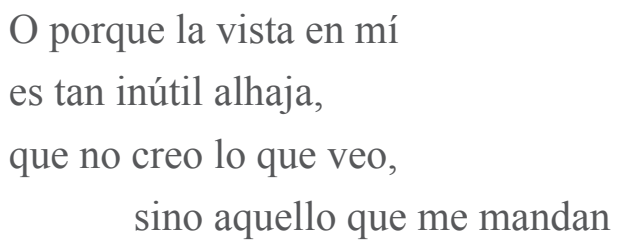

(Cruz, 1995, vv. 76-79)

Así, los contrastes entre ver y oír, entre el interior y el exterior de Hermenegildo, se reflejan en los contrastes creados por la combinación de metros, entre las 
Las marcas estructurales de el mártir del sacramento...

formas poemáticas recitadas y las cantadas, y se apoya de igual manera en aspectos escénicos que se encargan de resaltar la estructura interior/exterior del santo mártir que organiza el auto sacramental.

\section{Notas}

1 Respecto a la función estructural de la polimetría en los autos sacramentales, se puede revisar también Vitse 2006, Rull 2006, Gilbert 2006b, Antonucci 2006.

2 Para una mayor bibliografía, puede verse el estado de la cuestión de Fausta Antonucci (2010).

3 También puede verse el estudio sobre El pleito matrimonial del cuerpo y el alma, Mackenzie (2014). Hay que considerar que no todos los pasajes cantados son recitados por el anónimo personaje "Coro" o "Música" fuera de escena, sino que pueden ser parte de los parlamentos de personajes concretos

4 De los tipos de versificación que la Décima Musa utiliza, sólo tres de ellos son mencionados en El arte nuevo de hacer comedias, y dos, las octavas y el romance, según Lope de Vega, tienen la misma función: las relaciones (Vega Carpio, 2016, vv. 309-310), mientras que las décimas sirven para las quejas (Vega Carpio, 2016, v. 307).

5 Hay dos pasajes en sextinas, pero tienen estructura distinta: la lira sextina tiene la forma abbacC, mientras que la sextina del inicio es xaxaaA.

6 Basta echar un vistazo al corpus de autos calderonianos que la Universidad de Navarra y el GRISO han puesto en su página en internet: http://dspace.unav.es/ dspace/handle/10171/15994, al que remito por falta de espacio, pues se tratan de sesenta autos los que tienen indexados para consulta.

7 Las rimas alternadas é-i-o, que representan un verdadero alarde técnico de Sor Juana Inés de la Cruz(1995). Delatan la estructura de la forma métrica como un romancillo. Sólo un verso (“y de sus luces émulo" v. 941) podría considerarse suelto, aunque las vocales fuertes, é-o, mantienen la rima. El empleo de rimas asonantes con palabras esdrújulas no es común; no obstante, Antonio Alatorre (2007) 
recoge diversos testimonios durante el Renacimiento y el Barroco

8 Aunque pudiera pensarse que se trata de una combinación de heptasílabos y pentasílabos de rima alternada, no todos los versos tienen hemistiquio; también hay que considerar que los vv. 21 y 27 son endecasílabos que evitan tal estructuración del pasaje. Asimismo, queda la incógnita sobre esos dos versos, pues podrían considerarse un error de la monja, o bien como una decisión totalmente deliberada (lo cual anunciaría un significado más profundo o, en su defecto, tuvo la intención de resaltar los dos parlamentos).

9 Cuando cite acotaciones haré referencia al número de verso que sigue inmediatamente con la abreviación "acot."; además, respeto las cursivas con que el editor las apunta en su edición.

10 Un pasaje semejante en que se alternan redondillas cantadas y décimas recitadas se encuentra en El pleito matrimonial del cuerpo y el alma, mientras Cuerpo duerme (y se crea un espacio onírico), dos Coros, en redondillas cantadas, lo intentan convencer de seguir el camino de la salvación o el de la condena, creando un espacio fuera del tablado que podría interpretarse como el Cielo y el Infierno; Díez Borque ejemplifica la función de oposición de coros con este auto, que, como mencioné, es un caso paradigmático y bastante complejo al tomar en cuenta tanto los cambios métricos como las implicaciones escénicas.

11 Antonio Alatorre señala, además del uso de palabras esdrújulas en las rimas, que "la asonancia ha dejado prácticamente fuera de combate a la consonancia. En un románce en á-o, la palabra ánimo no tiene por qué rimar con magnánimo y pusilánimo: puede rimar con tráfago, áspero, cánticos, dándolo, párvulo y muchas otras voces" (2007, p. 246-247)

\section{Referencias}

Alatorre, A. (2007). "Versos esdrújulos". En Antonio Alatorre, Cuatro ensayos sobre arte poética (pp. 193-306). México: El colegio de México. 
Las marcas estructurales de el mártir del sacramento...

Antonucci, F. (2010). "La segmentación métrica, estado actual de la cuestión". Teatro de palabras, 4: 77-97. URL: http://www.uqtr.ca/teatro/teapal/TeaPalNum04Rep/TeaPal04Antonucci.pdf.

Antonucci, F. (2006). "La imbricación de lo visual y lo auditivo en la construcción de El verdadero Dios Pan”. En E. Cancelliere e I. Arellano (eds.) La dramaturgia de Calderón. Técnicas y estructuras (Homenaje a Jesús Sepúlveda) (pp. 25-39). Madrid/Frakfurt am main: Iberoamericana/Vervuert.

Arellano, I. y Duarte, J. E. (2003) El auto sacramental. Madrid: Ediciones del Laberinto.

Calderón de la Barca, P. (2012). La vida es sueño. Edición de las dos versiones del auto y de la loa. Fernando Plata Parga (ed.). Pamplona/Kassel: Universidad de Navarra/Reichenberger.

Cruz, sor J. I. de la. (1995). El mártir del sacramento, san Hermenegildo. En Autos sacramentales. Sergio Fernández y Alfonso Méndez Plancarte (eds.). México: Universidad Nacional Autónoma de México.

Díez Borque, J. M. (2000). “Teatro y fiesta en el Barroco español: El auto sacramental de Calderón y el público. Funciones del texto cantado”. En En J. A. Maydeu (ed.). Estudios sobre Calderón t. II (pp. 135-183). Madrid: Istmo.

Fernández Guillermo, L. (2013). "La trama polimétrica de El divino Narciso de sor Juana Inés de la Cruz”. En M. Insúa y M. Vinatea recoba. Teatro y fiesta popular y religiosa. (119-136). Pamplona: Servicios de publicaciones de la Universidad de Navarra. URL: http://dadun.unav.edu/bitstream/10171/35172/1/FernandezGuillermo.pdf

García Barrientos, J. L. (2007) Cómo se comenta una obra de teatro. $2^{\mathrm{a}}$ reimp. Madrid: Síntesis.

Gilbert, F. (2006a). "Polimetría y estructura dramática en el auto de Calderón El cordero de Isaías (1681), y sus consecuencias en la creación del espacio dramático." Criticón, 96, 167-179. 
Gilbert, F. (2006b). "Polimetría y estructuras dramáticas en el auto de Calderón Los encantos de la culpa (1645): las implicaciones dramáticas de una estructura binaria”. En O. Gorse y F. Serralta. El Siglo de Oro en escena. Homenaje a Marc Vitse. (pp. 363-381). Toulouse: Publications Universitaires du Mirail/Consejería de Educación de la Embajada de España en Francia.

Hernández Araico, S. (2008) "El montaje de El mártir del Sacramento: Sor Juana y san Hermenegildo, entre jesuitas y sevillanos", Destiempos, 14, 286-299. URL: http://www.destiempos.com/n14/hernandezaraico.pdf

Mackenzie, C. (2014) "La segmentación métrica de El pleito matrimonial del cuerpo y el alma: división y continuidad”. Signos literario, 19, 129-154.

Paz, O. (1982). Sor Juana Inés de la Cruz o Las trampas de la fe. México: Fondo de Cultura Económica.

Vega Carpio, F. L. (2016). Arte nuevo de hacer comedias. Felipe Pedraza Jiménez (ed.). Cuenca: Universidad de Castilla-La Mancha.

Vitse, M. (2006). "Métrica y estructura dramática en El gran teatro del mundo". En E. Cancelliere e I. Arellano (eds.). La dramaturgia de Calderón. Técnicas y Estructuras (Homenaje a Jésús Sepúlveda). (pp. 609-624). Madrid/ Frakfurt am main: Iberoamericana/Vervuert.

Vitse, M. (1998). "Polimetría y estructuras dramáticas en la comedia de corral del siglo XVII: el ejemplo de El burlador de Sevilla". En Ysla Campbell (ed.). El escritor y la escena VI. Estudios sobre teatro español y novohispano de los siglos de Oro. Actas del VI Congreso de la Asociación Internacional de Teatro Español y Novohispano de los Siglos de Oro. (pp. 45-63). Ciudad Juárez: Asociación Internacional de Teatro Español y Novohispano de los Siglos de Oro/Universidad Autónoma de Ciudad Juárez.

Worley, R. D. (2011). “La politización de la religión expuesta por Sor Juana Inés de la Cruz en el auto titulado El mártir del sacramento, san Hermenegildo", Bulletin of the comediantes, 63(1), 105-120. 


\section{¿Cómo citar este artículo?}

Mackenzie Rebollo, C.E. (Julio-diciembre, 2018). Las marcas estructurales de El mártir del sacramento, san Hermenegildo, de Sor Juana Inés de la Cruz: versificación, canto y escenografía. Revista humanidades, 8 (2), 1-17. doi: http://dx.doi.org/10.15517/h.v\%vi\%i.30715 